\title{
ÉTICA DA RESPONSABILIDADE COMO PILAR DA CIDADANIA NO SÉCULO XXI
}

\author{
Josélia Fonseca $^{1}$
}

\section{Resumo}

O desenfreado desenvolvimento científico e biotecnológico que se verifica ao longo da segunda metade do século XX e inícios do século XXI tem suscitado numerosas questões relativamente à preservação da integridade e dignidade da vida humana e à salvaguarda de toda a espécie de vida futura no planeta Terra.

A preocupação com a existência de Vida, tanto no presente como no futuro, exige a presença de uma (bio)ética cívica global, que favoreça o desenvolvimento de um agir eticamente responsável do cidadão do século XXI. Este tem sido classificado como um ser apático e inerte, pouco preocupado com o futuro da humanidade. Tal situação induznos a refletir sobre o terá conduzido a que numa sociedade democraticamente livre exista tanta inércia social. Do nosso ponto de vista, consideramos que a afirmação da liberdade como background da sociedade atual se releva insuficiente para a manutenção de uma cidadania ativa. Neste sentido, entendemos que é necessário que a ética da responsabilidade se afirme como princípio estruturante dos cidadãos comprometidos e empenhados com o desenrolar da vida comunitária, que se pretende global, justa, solidária. Assim, neste artigo, para além de analisarmos a pertinente exigência da (bio)ética cívica global, abordamos a necessidade de existir uma ética da responsabilidade se afirme como princípio estruturante dos cidadãos comprometidos e empenhados com o desenrolar da vida comunitária, que se pretende global, justa, solidária. Deste modo, problematizamos e discutimos o conceito de responsabilidade que se perfila para o século XXI e refletimos sobre o processo educativo que deve estar implicado na formação para a cidadania ativa e responsável.

Palavras-chave: Educação. Cidadania. Ética da Responsabilidade.

\section{ETHICS OF RESPONSIBILITY AS THE PILLAR OF CITIZENSHIP IN THE XXI $^{\text {th }}$ CENTURY}

\begin{abstract}
The unbridled scientific and biotechnological development that has taken place throughout the second half of the 20th century and the beginning of the 21 st century has raised many questions regarding the preservation of the integrity and dignity of human life and the safeguarding of all future life on Earth. Concern for the existence of Life, both now and in the future, requires the presence of a global (bio) civic ethic, which favors the development of a critical and reflexive moral consciousness that is the driving force of deliberating and acting ethically responsible of the citizen of the $21 \mathrm{st}$ century. This has been classified as an apathetic and inert being, little concerned with the future of humanity. Such a situation induces us to reflect on what has led to such a social inertia in a democratically free society. From our point of view, we consider that the affirmation of freedom as the background of current society is insufficient for the

\footnotetext{
${ }^{1}$ Prof. Dra. Josélia Mafalda Ribeiro Fonseca, é professora auxiliar no Departamento de Ciências da Educação na Universidade dos Açores em Portugal. E-mail: joseliamafaldarf@ gmail.com.
} 
maintenance of an active citizenship. In this sense, we understand that it is necessary that the ethics of responsibility be affirmed as a structuring principle of citizens committed and committed to the development of community life, which is intended to be global, fair and supportive.Therefore, in this article, in addition to analyzing the pertinent requirement of global (bio) civic ethics, we address the need for an ethics of responsibility to be affirmed as a structuring principle of citizens committed and committed to the development of community life, which is intended globally, Fair, solidary. In this way, we discuss and discuss the concept of responsibility that is emerging for the 21 st century and reflect on the educational process that must be involved in training for active and responsible citizenship.

Keywords: Education. Citizenship. Ethics of Responsibility

\section{A necessidade de uma (bio)ética cívica global}

A evolução cientifica, tecnológica e as consequentes alterações sociais, vinculadas à necessidade de um diálogo universal consciente e responsável, que seja simultaneamente equilibrador de um desmesurado poder de forças, tornou premente o surgimento de uma (bio)ética global. Esta deverá ser entendida como um ethos comum,

[...] um conjunto de princípios, valores, crenças, ideais, e utopias partilhados por toda a Humanidade ou à volta dos quais fosse possível estabelecer um consenso vinculador e vinculativo de forma a garantir não só a paz entre os homens mas também uma resposta eficaz. (Patrão-Neves e Osswald, 2014, p. 303-4).

Na verdade, esta ética global assume-se como fiel da balança de uma sociedade pautada pelo pluralismo axiológico, impulsionador, em certo sentido, do niilismo e em que o relativismo moral e de valores se torna apanágio da comunidade do "homem light” (Rojas, 1994), mais preocupado com o hedonismo individual do que com a unidade e o bem comunitários.

Neste contexto de vazio de valores, que Patrão-Neves e Walter Osswald (2014, p. 312) designam de "descrédito generalizado nos valores tradicionais [e] ausência de um fundamento, universal da moral", a ética global que é exigida para o século XXI imprime ao conceito de bioética um novo sentido, o de uma ética cívica. Na realidade, o conceito de bioética do século XXI não se reporta apenas às questões ecológicas e médicas, como se verificou no século $\mathrm{XX}$, mas assume uma conotação social, que evidencia a preocupação no estabelecimento de consensos alargados, consubstanciados num forte sentimento de pertença que é motivador de um processo de participação e deliberação ativo e responsável.

\begin{tabular}{|l|l|l|l|l|}
\hline Q Rovista Dialectus & Ano 4 & n. 10 & Janeiro - Julho 2017 & p. 184-199 \\
\hline
\end{tabular}


Enquanto ética cívica, a bioética procura, no contexto das sociedades axiologicamente plurais, ser legitimadora da ação e do processo deliberativo de todos os cidadãos, em busca do que é consensual para o bem comum. Na verdade, a bioética, como ética cívica,

[...] pode ser primeiramente entendida como uma moral comum. Isto é, uma experiência moral partilhada de uma comunidade implícita na vivência quotidiana dos seus membros de uma mesma comunidade. Neste sentido, trata-se de uma moral substancial, ou seja, que exprime uma concepção de bem; tratar-se ia de uma ética dos máximos [...] que exorta o ideal de acção. (Patrão-Neves e Osswald, 2014, p. 314-15)

A ética dos máximos a que se refere Patrão-Neves e Walter Osswald situa-se na mesma linha da concebida por Adela Cortina $(1989,2001)$ como os princípios ideais de ação que visam com bem supremo, o convite à Felicidade. A ética dos máximos reporta-se a "propostas de vida feliz" (Cortina, 2001, p. 140), neste sentido podemos afirmar que se refere a uma dimensão mais formal e subjetiva da ética, na medida em que os graus de felicidade são diferentes de pessoa para pessoa, de sociedade para sociedade. Segundo Adela Cortina (2000, p.139), a felicidade é um conceito vazio, fruto da imaginação, "todos os homens aspiram a felicidade mas não a entendem de igual modo, nem leigos nem sábios, nem jovens nem adultos, nem as distintas sociedades entre si."

A ética dos máximos não é a que melhor se coaduna com as exigências e com as necessidades da sociedade global tecnológica e axiologicamente descrente do novo milénio, na medida em que a reflexão e a resposta do cidadão aos problemas e desafios do mundo atual exige uma tomada de consciência e uma ação eticamente esclarecida, que se consubstancie em princípios estruturantes e essenciais à vida e à dignidade humana no planeta Terra. Isto é, o contexto tecnológico e sociocultural do século XXI exige a presença de uma (bio)ética cívica, que deve assentar no que Adela Cortina (1989, 2001) designa ética dos mínimos, nos princípios indispensáveis à salvaguarda do bem de todos, como sejam os mínimos de igualdades, de justiça para que todos sejam tratados com dignidade.

Esta ética cívica consiste, na verdade numa ética procedimental, em que se procura estabelecer o que pode ser consensualmente aceite e legitimado por todos como

\begin{tabular}{|l|l|l|l|l|}
\hline Q Ronista Dialectus & Ano 4 & n. 10 & Janeiro - Julho 2017 & p. 184-199 \\
\hline
\end{tabular}


práticas sociais viáveis, não lesáveis da integridade humana nem da vida, no sentido mais lato do termo.

A ética procedimental a que nos reportamos deve ser entendida na linha do que Jürgen Habermas e Karl-Otto Apel concebem a ética do discurso e a ética da responsabilidade respetivamente, como um processo dialógico de ação que aspira e realiza o bem.

A ética do discurso e da responsabilidade de Habermas e Apel consistem numa interpretação intersubjetiva do imperativo categórico kantiano, visam desencarcerar este imperativo do carácter monológico a que lhe estava conferido e imprimi-lhe uma dimensão construtiva e coparticipada. Ao homem não basta agir tendo em vista a “pessoa como fim em si mesmo", é também necessário que tome medidas e decisões que garantam esta premissa. Isto é, não é suficiente que exista uma regra formal que oriente a ação humana em prol do consenso e do bem comum, é necessário que existam mecanismos que façam vigorar essa regra e que ela seja uma realidade concreta e aplicável.

É neste sentido que caminha a ética do discurso de Habermas e Apel,

[...] na ética do discurso, o método de argumentação moral substitui o imperativo categórico. É ela que formula o principio «D»: as únicas normas que têm direito a reclamar validade são aquelas que podem obter anuência de todos os participantes envolvidos num discurso prático. O imperativo categórico desce ao mesmo tempo na escala transformando-se num princípio de universalização «U», [...] nos casos das normas em vigor, os resultados e as consequências secundárias, provavelmente decorrentes do cumprimento geral dessas mesmas normas e a favor dos interesses de cada um, terão de poder ser aceites voluntariamente por todos. (Habermas, 1999, p.16).

Deste modo, concordamos com Adela Cortina (2002) quando afirma que a “Teoria dos Discurso habermasiana coloca em funcionamento a fórmula kantiana do contrato social", pois, na verdade, o que se verifica com a ética do discurso é a materialização do imperativo categórico kantiano, é a busca de um entendimento ético (Habermas, 2007) sob a égide da justiça, da igualdade e da solidariedade.

O consenso moral e o ethos que consubstanciam o processo deliberativo apoiado na ética do discurso parte do pressuposto de que todas as pessoas têm os mesmos direitos, devem ser igualmente respeitadas e que é correto (justo) que o consenso normativo ocorra nestas condições.

\begin{tabular}{|l|l|l|l|l|}
\hline Q Rovista Dialectus & Ano 4 & n. 10 & Janeiro - Julho 2017 & p. 184-199 \\
\hline
\end{tabular}


Não obstante reconhecermos a importância dos princípios da igualdade, da solidariedade e da justiça no estabelecimento de consensos morais e no desenvolvimento de uma ética cívica, entendemos que estes não são suficientes para a promoção da participação ativa dos membros de uma determinada comunidade.

A igualdade, a solidariedade e a justiça são fundamentais para legitimar a racionalidade ética das normas morais da sociedade e a colaboração dos seus membros na sua construção, mas não são garante da participação efetiva dos cidadãos nesse processo construtivo.

Em nenhum outro período histórico se falou tanto de passividade dos cidadãos. Uma passividade insólita num momento e num contexto social, político, axiológico conturbado, pluralista, desafiante, que convidam o cidadão a intervir e a responder aos desafios da sociedade tecnológica global.

Esta situação denuncia que os princípios de igualdade, solidariedade e justiça já outorgados pela carta dos direitos do homem e do cidadão, do século XVIII, e consolidados no século XX pela Declaração dos Direitos do Homem (1948) não são plenamente reconhecidos pelos cidadãos do século XXI. Como referimos num trabalho anterior (Fonseca, 2011), estes demitem-se de participar na resolução dos problemas da sua sociedade porque se sentem confortavelmente protegidos pelo Estado de Bem-estar Social, menosprezando o sentido de pertença comunitária e as exigências que este sentimento acarreta.

Assim sendo, e sem negligenciar a importância que os princípios da autonomia, da igualdade, da justiça e da solidariedade desempenham para a unidade e bem social, entendemos que no contexto pluralista e desafiante da sociedade global é importante eleger um novo pilar axiológico que, associado aos anteriores (autonomia, igualdade, solidariedade e justiça), promova a tomada de consciência do cidadão como membro da sociedade e como ser interveniente e ativo, trata-se do princípio ético da responsabilidade.

\section{Que responsabilidade para a sociedade do século XXI?}

A eleição da ética da responsabilidade como princípio estruturante da sociedade exigente e global deste milénio sugere-nos a reflexão e o esclarecimento concetual do que se preconiza ser o sentido desta responsabilidade.

Como é comumente conhecido, o conceito de responsabilidade surge primeiramente no domínio jurídico, assumindo o sentido de punição e de reparação. O

\begin{tabular}{|l|l|l|l|l|}
\hline Q Rovista Dialectus & Ano 4 & n. 10 & Janeiro - Julho 2017 & p. 184-199 \\
\hline
\end{tabular}


homem, enquanto ser de ação, deve ser imputado pelos atos que realiza e em caso de causador de dor ou dano tem a obrigação de reparar erro cometido, beneficiando a vítima do malefício.

Embora reconheçamos a importância da dimensão jurídica para a clarificação do conceito de responsabilidade, dada a natureza ético-moral deste trabalho, não lhe dedicaremos minuciosa atenção, centraremos a nossa análise reflexiva na aceção ética do termo e na sua evolução histórico-filosófica, com o intuito de compreender qual a conceção de responsabilidade que melhor se coaduna às exigências da sociedade do novo milénio.

No nosso entender, e influenciadas pela filosofia de Hans Jonas (1995) na obra Le principe responsabilité. Une éthique pour la civilisation technologique, o conceito de responsabilidade das tradicionais éticas teleológicas (Aristóteles) e deontológica (Kant e os que prosseguiram na mesma linha conceptual a ética do discurso de Apel e Habermas) não é suficiente para fazer frente ao desenfreado progresso científico e tecnológico da sociedade do século XXI e às consequências ameaçadoras deste. De acordo com Jonas (1995, p. 13) "a nova terra da prática coletiva, na qual nós entramos com a tecnologia de ponta, é ainda uma terra virgem de teoria ética.”

Na perspetiva das éticas teleológicas, de inspiração aristotélica, a responsabilidade reporta-se ao sentido de imputação. Aristóteles, em Ética a Nicómaco, entende a responsabilidade sob o ponto de vista de causa-efeito, o homem é a causa das suas ações e daí deriva a sua responsabilidade.

Para as éticas deontológicas, a responsabilidade (imputabilidade) assume uma dimensão moral, ela é correlato da liberdade e, na filosofia kantiana, liberdade e imputabilidade "coincidem na instauração da obrigatoriedade de agir de acordo com a lei." (Patrão-Neves, 2001, p.853)

Segundo Habermas (2007, p. 174), "a ética discursiva justifica o conteúdo de uma moral do igual respeito e da responsabilidade solidária para com todos." No âmbito da ética do discurso, a responsabilidade é concebida sob o ponto de vista da solidariedade e perspetivada como mote de uma ação e de construção da lei moral e política que visa o estabelecimento da reciprocidade do dever na resolução do problema existente.

[...] quem pisar o solo do discurso com uma questão séria não supõe apenas automaticamente a igualdade de direitos de todos os virtuais parceiros «de discurso, mas também algo assim como

\begin{tabular}{|l|l|l|l|l|}
\hline Q Rovista Dialectus & Ano 4 & n. 10 & Janeiro - Julho 2017 & p. 184-199 \\
\hline
\end{tabular}


uma solidariedade da responsabilidade na solução do problema. (Apel, 2007, p. 324)

Embora distintas, as éticas tradicionais (teleológicas e deontológicas) defendem uma noção de responsabilidade antropocêntrica, centrada nas relações de reciprocidade intersubjetiva, tanto a nível individual como a nível coletivo, temporal e espacialmente voltada para ações passadas e nem a humanidade nem o planeta podem estar sujeitos às consequências da ação, sobretudo num contexto do poder desenfreado da ciência e da tecnologia da sociedade vigente.

O mundo tecnológico contemporâneo caracteriza-se pelo triunfo do homo faber sobre o homo sapiens, (Jonas, 1995), do homem sedento de sucesso e de poder sobre o homem eticamente consciente e esclarecido, a sociedade atual está sobre a hegemonia do homem que relega para segundo plano as preocupações com a sobrevivência da humanidade, em prol do crescente prestígio e do poder. O homem tornou-se um “[...] Prometeu desagrilhoado a quem a ciência nunca atribuiu poderes conhecidos e a economia dá o infatigável impulso" (Jonas, 1995, p. 13). Este "Prometeu desagrilhoado" contemporâneo mais do que roubar o fogo e desafiar os deuses, coloca, com o seu ilimitado poder tecnológico, em risco a natureza, a preservação da vida e a sobrevivência da humanidade.

É neste contexto que se revela pertinente a emergência da ética da responsabilidade jonassiana, uma ética prospetiva, que visa o "[...] refreamento voluntário do seu poder impeça o ser humano de cair em desgraça [...]" (Jonas, 1995, p.13).

A responsabilidade que se refere Jonas não se reporta apenas ao passado e ao presente da ação humana, o filósofo defende uma responsabilidade não recíproca voltada para o futuro preocupada com os mais vulneráveis e com as gerações vindouras.

É neste sentido que Jonas elabora o seu imperativo ético, “Age de tal forma que os efeitos da tua acção sejam compatíveis com a permanência de uma vida autenticamente humana sobre a terra" (Jonas, 1995, p. 30). Ou ainda na forma de expressão negativa deste imperativo, "Não comprometas as condições da sobrevivência indefinida da humanidade sobre a terra; inclui na tua escolha actual a integridade futura do homem como objecto secundário do teu querer." (Jonas, 1995, p. 30-31).

$\mathrm{Na}$ verdade, o que Jonas pretende garantir com o seu imperativo é "que a humanidade seja" (Jonas, 1995, p. 30). E o homem tem não apenas o dever, como se

\begin{tabular}{|l|l|l|l|l|}
\hline Q Povista Dialectus & Ano 4 & n. 10 & Janeiro - Julho 2017 & p. 184-199 \\
\hline
\end{tabular}


verificava na filosofia kantiana, mas, acima de tudo, o poder de responder perante a vulnerabilidade dos mais fracos e dos perecíveis no presente, cuidando para que as gerações vindouras possam ser. Ao contrário do que se verifica na ética kantiana, a responsabilidade não é um correlato da liberdade, ela é o princípio estruturante do princípio da vida no planeta e de uma vida com garantia de dignidade.

O princípio de responsabilidade voltada para o futuro a que se refere Jonas tem um fundamento, não ético nem político, ontológico. Esta dimensão ontológica manifesta-se na preocupação da manutenção e da existência da vida em si e no dever do homem em responder à permanente necessidade de atualizar a sua potência de ser e de garantir que os outros também o sejam.

Como refere Jonas (1998, p.81),

A responsabilidade terá a ver agora e sempre com o Ser, entendido não só no sentido passivo, como objecto transformável do meu agir, mas também no sentido activo, como o sujeito permanente de um apelo que me arrebata de um dever.

A ética da responsabilidade jonassiana ao fundamentar-se num substrato ontológico distingue-se do imperativo categórico de kantiano, que Jonas define como meramente lógico e formal, pois, a filosofia deste último filósofo pretende uma ética universal, mas "não para que todos os homens ajam e pensam da mesma maneira mas porque assim defende a vida e a dignidade humana." (Fernandes, 2004, p. 32)

A responsabilidade de Jonas também se distingue da ética solidária postulada pela ética do discurso de Habermas e Apel. Estes também perspetivam uma ética da responsabilidade voltada para o futuro, preocupada com a sobrevivência da humanidade. "Afirma Apel (2007, p. 151) que a "fundamentação final da ética do discurso contém [...] uma fundamentação racional do postulado de Hans Jonas, que também no futuro haverá uma humanidade."

No entanto, esta conceção de responsabilidade da ética do discurso tem uma dimensão procedimental, visa a constituição de normas e regras consensuais de ação que garantam a vida presente e futura da humanidade. O discurso argumentativo é um

[...] meio indispensável para a fundamentação de normas consensuais da moral e do direito [...]. Pois o [...] o [que] se trata é de assumir a responsabilidade solidária pelas consequências e subconsequências à escala mundial das

\begin{tabular}{|l|l|l|l|l|}
\hline Q Rovista Dialectus & Ano 4 & n. 10 & Janeiro - Julho 2017 & p. 184-199 \\
\hline
\end{tabular}


actividades colectivas dos homens [...] e de organizar a responsabilidade como praxis colectiva (Apel, 1995, p. 148).

Não obstante entendermos que a responsabilidade é um princípio essencial e estruturante de toda e qualquer sociedade e que, por isso mesmo, deve ser fundamento das leis morais que visam consensualmente o bem de todos, consideramos também que toda e qualquer pessoa deve ser co naturalmente interpelada pelo sentimento da responsabilidade e deve ter consciência deste apelo que a leva a responder ao seu desafio de ser e ao desafio do Bem ser, no sentido de criar condições para que a humanidade seja.

A responsabilidade não deve ser algo artificial que é imposto extrinsecamente aos sujeitos de ação. Se assim o for, poderá não estar salvaguardado o Bem em si, sobretudo num período em se assiste ao desenfreado poder tecnológico que constrange a vida humana à destruição.

Mais do que uma responsabilidade artificial, é necessário uma responsabilidade ontológica, o que Jonas designa de substancial, uma responsabilidade que atende ao Bem enquanto Bem, que fala à consciência de pessoa e que a leva agir com os outros em prol do bem comum.

Não é a obrigação que é objecto [da moral]; não é a lei moral que motiva o agir moral, mas o apelo do bem em si possível no mundo que dirige face ao meu querer e que exige ser escutado em conformidade à lei moral. Escutar este apelo é o que ordena a lei moral (Jonas, 1995, p. 123).

$\mathrm{Na}$ realidade, acreditamos que só esta responsabilidade substancial que é conatural à existência humana e que, por isso mesmo se assemelha à responsabilidade parental, do dever global e infinito do pai sobre o filho instituído desde o nacimento deste, pode impulsionar o homem do século XXI a responder perante os desafios da sociedade, a ser um cidadão ativo.

Não obstante reconhecermos a pertinência desta ética da responsabilidade para o desenvolvimento do cidadão ativo deste milénio, que se pretende que seja interventivo, também entendemos que não podemos correr o risco de deixar o futuro da humanidade sob a égide da responsabilidade substancial, pois o homem pode demitir-se sua responsabilidade global, conatural. A esta responsabilidade substancial deverá juntar-se a responsabilidade solidária que está associada à ética do discurso, no sentido em que é importante que cada ser humano tenha consciência da sua responsabilidade e aja

\begin{tabular}{|l|l|l|l|l|}
\hline Q Rovista Qialectus & Ano 4 & n. 10 & Janeiro - Julho 2017 & p. 184-199 \\
\hline
\end{tabular}


naturalmente fazendo uso dela, assim como é importante que existam normas e leis, que consensual, garantam com justiça a prática dessa responsabilidade.

Neste sentido, revela-se muito importante o desenvolvimento de um processo educativo que promova o desenvolvimento da personalidade humana no reconhecimento da sua responsabilidade, como elemento integrante desse desenvolvimento; e não apenas que apresente o conjunto de leis morais e coaja os cidadãos a obedecê-lo, sem compreender o real sentido da sua existência. A força motriz que leva à ação humana deve ser uma responsabilidade intrínseca e imanente, que deve ser desvelada no percurso da existência, e não uma responsabilidade que é imposta extrinsecamente pela coação da lei.

\section{Como educar para a cidadania ativa e responsável?}

A eleição da ética da responsabilidade como princípio impulsionador de uma cidadania ativa para o século XXI parece ser duplamente redundante. Desde a sua origem, Grécia do século V a.C., que sempre esteve associado ao conceito de cidadania a conotação de participação, pro-atividade. $O$ cidadão grego era o ateniense que participava na vida da pólis (cidade-estado). Para além disso, e ainda que segundo outros contornos, assumindo o sentido de imputação e causa-efeito da ação, o conceito de responsabilidade também sempre esteve associado ao processo deliberativo do cidadão da polis. O homem é o aitios dos seus atos e, enquanto causa dos seus atos, ele tinha a obrigação de os assumir e de responder por eles.

O que é facto é que a expressão "cidadania ativa" tornou-se recorrente neste novo milénio. Adela Cortina (1999), na obra Los Cuidadanos como Protagonistas, caracteriza o cidadão dos finais do século XX e inícios do século XXI como passivo e acrítico, um ser " dependente [...] apático e medíocre, alheio a todo o pensamento de livre iniciativa, responsabilidade ou empresa criadora." (Cortina, 1999, p. 28)

A referência à passividade dos cidadãos e o reconhecimento da necessidade de um maior nível de responsabilidade que estimule a sua pro-atividade não se restringe ao contexto político e social. No âmbito educativo, tanto nacional como internacionalmente, tem sido recorrente a bibliografia específica deste domínio mencionar a pertinência em promover a formação do cidadão como membro ativo e responsável da sua comunidade.

Em Portugal, o Conselho Nacional de Educação publica, em 2004, o Relatório do Saberes Básicos do Cidadão do Século XXI, no qual indica a cidadania ativa como um

\begin{tabular}{|l|l|l|l|l|}
\hline Q Rovista Dialectus & Ano 4 & n. 10 & Janeiro - Julho 2017 & p. 184-199 \\
\hline
\end{tabular}


desses cinco saberes, enfatizando a dimensão axiológica, nomeadamente a ética da responsabilidade, com um dos pilares essenciais dessa cidadania.

Segundo este relatório a "cidadania ativa" deve ser preconizada como:

[...] agir responsavelmente sob o ponto de vista pessoal e social no quadro das sociedades modernas que se querem abertas e democráticas [...]. Aqui se privilegia a vertente axiológica, de forma a agir no quadro de uma ética da responsabilidade, solidariedade e tolerância. Saber lidar adequadamente com diferenças culturais e de géneros passa por aqui, bem como a sensibilização para a importante vertente do desenvolvimento sustentável, envolvendo [...] a harmoniosa relação homem/natureza. Trata-se de desafiar o actual sentido da globalização [...] que deve também incorporar a globalização, da liberdade, da justiça e da solidariedade (Cachapuz, SáChaves \& Paixão, 2004, p. 29).

$\mathrm{Na}$ verdade, o que o Conselho Nacional de Educação defende com a educação para a cidadania ativa é um processo educacional que promova a aquisição de conhecimentos, o desenvolvimento de competências e valores, que favoreçam a formação de uma consciência reflexiva e ética dos alunos, no sentido de os preparar para viverem democraticamente, sabendo conviver com a globalidade e com a diferença, sendo membros comunitários interventivos, solidários e responsáveis capazes de resolver conscientemente problemas e de ter preocupações ambientais.

A manifestação explícita e veemente da formação para a cidadania ativa induznos a questionar sobre o que deve ser feito no processo educativo para que esta exigência se cumpra?

Ainda que assumindo diferentes contornos, a educação teve desde sempre uma dimensão antropológica e ética, visava a formação do homem tendo em vista a sua inserção social.

Esta dimensão antropológica e ética enfatiza-se na segunda metade do século XX, depois dos horrores cometidos contra a humanidade no holocausto e da afirmação da democracia por toda a Europa Ocidental. Verifica-se que há um investimento na educação como meio que promove o desenvolvimento pessoal e social do homem, como um ser livre e digno.

O $26^{\circ}$ artigo da Declaração dos Direitos Humanos (1948), consagra a educação como um direito universal do Homem definindo que esta deve ter como finalidade "[...] a plena expansão da personalidade humana e o reforço dos direitos do homem e das

\begin{tabular}{|l|l|l|l|l|}
\hline Q Rovista Dialectus & Ano 4 & n. 10 & Janeiro - Julho 2017 & p. 184-199 \\
\hline
\end{tabular}


liberdades fundamentais." Em 1976, a assinatura do Pacto Internacional sobre os Direitos Civis e Políticos reforça a dimensão de participação consciente e responsável dos cidadãos que está associada à educação, quando, altera o artigo $26^{\circ}$ supracitado, e acrescenta como finalidades educacionais o sentido da dignidade e a preparação do Homem para agir na sociedade livre.

A preparação do homem para agir e deliberar em contexto comunitário livre exige que o processo educativo se centra na formação do Homem como Pessoa, no sentido ético do termo, entendida como a unicidade dinâmica do eu singular e do eu comunitário. Isto é, como uma identidade que se constrói na interação dialética entre o ser único e irrepetível que é cada ser humano e a sua dimensão social, o saber ser e viver com os outros.

A construção deste processo identitário pressupõe a existência de um quadro axiológico que permita a cada Homem olhar para a sua singularidade, a responder conscientemente ao apelo ser, zelando pela sua integridade e dignidade, e a olhar para o outro como igual a si mesmo, reconhecendo idênticos direitos e respondendo perante a sua solicitude e sua a vulnerabilidade.

$\mathrm{Na}$ verdade, ser pessoa é ser cidadão. Como refere Ferreira Patrício, numa entrevista publicada por Luís Sebastião e Maria Teresa Santos (2006, p. 1999), que "Ser pessoa é ser com-pessoa ou pessoa-com, em que o "com" assinala a presença, a necessidade, apelo do outro e orientação para o outro. A pessoa autêntica e plena é pois [...] portadora da dimensão da cidadania".

A educação enquanto processo que visa o pleno e global desenvolvimento da personalidade humana tem, indubitavelmente, o dever de preparar o Homem para exercer a sua cidadania.

O exercício da cidadania que, no nosso entender, exige, para além da autonomia pessoal, um conatural sentido de pertença que exorta uma ética da responsabilidade no sentido que falamos anteriormente.

O desenvolvimento desta ética da responsabilidade no processo educativo implica, segundo o nosso ponto de vista, alterações estruturais no domínio educacional: o entendimento consensual dos professores sobre o que consiste educar, reconhecendo-o como um processo que visa a formação da Pessoa na sua dimensão singular e comunitária e que, em função disso, não se pode restringir a uma prática instrutiva; a criação de condições que promovam o desenvolvimento de uma práxis docente crítica e

\begin{tabular}{|l|l|l|l|l|}
\hline Q Povista Dialectus & Ano 4 & n. 10 & Janeiro - Julho 2017 & p. 184-199 \\
\hline
\end{tabular}


reflexiva, em que o professor, pela análise contextualizada da sua situação educativa, se sinta coresponsabilizado pela formação dos seus alunos e responda às suas necessidades no domínio da atual sociedade global e tecnológica; o desenvolvimento da consciência reflexiva do professor sobre as suas práticas educativas permitirá também que ele concebe o currículo como um conjunto de princípios norteadores da sua ação educativa, que podem e devem ser adequados às necessidades do seu contexto educacional, isto é, possibilitar-lhe-á criar situações e condições educativas facilitadoras de um processo de construção ativa do conhecimento por parte dos alunos, que envolve o desenvolvimento de uma consciência moral progressivamente mais autónoma na resolução dos problemas.

$\mathrm{Na}$ realidade, entendemos que a ética da responsabilidade que se assinala como elemento estruturante no desenvolvimento da cidadania da sociedade global, tecnológica e axiologicamente plural do século XXI, perspetiva o desenvolvimento de uma escola cidadã, em que todos os membros da comunidade educativa são corresponsabilizados pelo processo educacional e interpelados a criarem situações facilitadores da apropriação ativa do saber e do desenvolvimento da racionalidade crítica, (Perrenoud, 2002), dos professores e dos alunos.

O desenvolvimento desta escola cidadã implica que os professores devem conceber a cidadania como conatural e intrínseca ao desenvolvimento humano. Assim sendo, a cidadania não deve ser imposta de fora aos alunos, como um conjunto estruturado de normas e regras que ele tem que saber e cumprir acriticamente, sem compreender o seu sentido, sem as discutir e sem as refletir. Isto é, sem a formação de uma consciência ética e axiológica, facilitadora do desenvolvimento nos alunos de um sentido de pertença social e impulsionadora do reconhecimento da responsabilidade substancial, que mencionamos anteriormente, em que cada um se sente impelido a responder perante o apelo e a vulnerabilidade do outro. Os professores têm a responsabilidade de criar condições educativas em que os alunos sejam levados à constituição de uma racionalidade crítica e de um desenvolvimento moral que transcenda o que Kohlberg designa de estádio convencional.

\section{Trilhando conclusões para uma ética da responsabilidade cívica...}

A afirmação da ética da responsabilidade como pilar estruturante da cidadania do século XXI ocorre numa conjuntura sociocultural complexa, na qual entendemos que ser livre não é condição suficiente para a participação ativa do cidadão.

\begin{tabular}{|l|l|l|l|l|}
\hline Q Rovista Dialectus & Ano 4 & n. 10 & Janeiro - Julho 2017 & p. 184-199 \\
\hline
\end{tabular}


O cidadão atual, confortavelmente instalado no Estado de Bem-estar Social e inebriado pela sede de poder, revela-se do ponto de vista social e ético um ser passivo e apático. No nosso entender, esta apatia deve-se ao facto de não compreender a cidadania como algo intrínseco ao seu desenvolvimento enquanto Pessoa.

A Pessoa, enquanto categoria ética, constrói-se ao longo do percurso existencial do ser humano na resposta ao apelo de ser e na relação intersubjetiva, na qual também é responsável pelo que o Outro seja.

É neste sentido que se perspectiva a ética da responsabilidade, como resposta de cada eu à interpelação de ser com e pelos outros, tanto no presente como prospectivamente, criando condições para que futuramente haja vida saudável na Terra e a humanidade seja (Jonas, 1995)

Cada ser humano tem de aprender a "escutar" a voz da responsabilidade, que lhe é intrínseca e conatural à sua existência e que lhe permitirá prosseguir com a sua progressiva realização em comunidade.

Cabe à educação, enquanto processo que promove o desenvolvimento da personalidade como identidade que se constrói na unicidade dinâmica do eu singular e do eu comunitário, favorecer o desenvolvimento desta responsabilidade substancial.

Para a concretização desta finalidade, o processo educativo deve potenciar uma formação em que a cidadania não seja compreendia como uma realidade que é extrínseca à Pessoa, mas como algo que é constitutivo do seu ser; e em que a responsabilidade não seja perspetivada apenas como imputação, mas como motor da atividade de um ser que deve responder às solicitações da sociedade a que ele pertence e que reconhece pertencer.

Para que tal ocorra é necessário que se conceba a educação como um processo que transcende a instrução e a imposição de normas e regras sociais e visa, pela apropriação ativa de conhecimentos, o desenvolvimento de uma consciência moral e cívica progressivamente autónoma, crítica, reflexiva e motivadora da ação.

\section{Referências bibliográficas:}

APEL, K-O. Éthique de la discussion. Paris: Éditions du Cerf, 1994.

APEL, K-O. Ética e Responsabilidade. O problema da passagem para a moral pósconvencional. Lisboa: Instituto Piaget, 2007.

\begin{tabular}{|l|l|l|l|l|}
\hline Q Ronista Dialectus & Ano 4 & n. 10 & Janeiro - Julho 2017 & p. 184-199 \\
\hline
\end{tabular}


ARISTÓTELES. Ética a Nicómaco. Lisboa: Quetzal Editores, 2004.

CACHAPUZ, A., SÁ-CHAVES, I. e PAIXÃO, F. Saberes básicos de todos os cidadãos no século XXI. Lisboa: Conselho Nacional de Educação - Ministério da Educação, 2004.

CORTINA, A. Ética mínima. Madrid: Editorial Tecnos, 1989.

CORTINA, A. Los ciudadanos como protagonistas. Barcelona: Galaxia Gutemberg Circulo de Lectores, 1999.

Cortina, A. (2001) Alianza y Contrato. Madrid: Editorial Trotta.

Cortina, A. La dimensión publica de las éticas aplicadas. In: Revista Iberoamericana de Educacíon, $\mathrm{n}^{\circ}$ 29, 2002, pp.45-64.

Fernandes, M. O «Princípio Responsabilidade» de Hans Jonas: em Busca dos Fundamentos da Ética da Educação Contemporânea. In: Nascimento, E. et. al, (Org.). Ética à Utopia em Educação. Porto: Edições Afrontamento, 2004.

Fonseca, J. A cidadania como projecto educacional: uma abordagem reflexiva e reconstrutiva. Tese de doutoramento. Angra do Heroísmo, Universidade dos Açores, 2011.

Habermas, J. Comentários à ética do discurso. Lisboa: Instituto Piaget, 1999.

Habermas, J Ética discursiva. In: Gómez C. (Ed.) Doce textos fundamentales de la Ética del siglo XX. Madrid: Alianza Editorial, 2007.

Jonas, H. Le principe responsabilité. Une éthique pour la civilisation technologique. Paris: Éditions du Cerf, 1995.

Jonas, H. Pour une éthique du futur. Paris: Éditions Payot \& Rivages,1998.

Patrão-Neves, M. C. (2001). Na senda da responsabilidade moral. In Poiética do Mundo. Homenagem a Joaquim Cerqueira Gonçalves. Lisboa: Edições Colibri.

Patrão-Neves, M. C. e Osswald, W. Bioética Simples. Lisboa: Verbo, 2014.

Perrenoud, P. A escola e a aprendizagem da democracia. Rio Tinto: Edições Asa, 2002.

\begin{tabular}{|l|l|l|l|l|}
\hline Q Ponista Dialectus & Ano 4 & n. 10 & Janeiro - Julho 2017 & p. 184-199 \\
\hline
\end{tabular}


Rojas, E. O Homem Light: uma vida sem valores. Coimbra: Gráfica de Coimbra, 1994.

Sebastião, L e Santos, M. T. Manuel Ferreira Patrício: a construção da escola do nosso contentamento. In: Educação - Temas e Problemas, $\mathrm{n}^{\circ}$ 2, 1, 2006, p. 197203.

\begin{tabular}{|l|l|l|l|l|}
\hline Q Rovista Dialectus & Ano 4 & n. 10 & Janeiro - Julho 2017 & p. 184-199 \\
\hline
\end{tabular}

